COMMENT

https://doi.org/10.1057/s41599-020-0395-6

\title{
Practical considerations for establishing writing groups in interdisciplinary programs
}

Nicole Bergen (ib) ${ }^{1 \star}$, Alzahra Hudani ${ }^{1}$, Selim Khan ${ }^{1}$, Natalie D. Montgomery ${ }^{1} \&$ Tracey O'Sullivan ${ }^{1}$

\begin{abstract}
Academic writing capabilities are a cornerstone of success in doctoral programs, yet prove to be a point of anxiety and apprehension for many students. Providing support for academic writing within interdisciplinary programs poses special considerations, as students in these programs are called upon to transcend single disciplinary perspectives to address a central area of research, and to integrate multiple different disciplinary perspectives that may be conflicting or overlapping. When treated as a social practice, writing can serve as a common interest that draws doctoral students to convene and develop in their learning. This article describes the development of a student writing group in an interdisciplinary doctoral program, considering how the characteristics and activities of the group create an environment that enables and encourages enhanced interdisciplinary learning. The article argues that, when delivered successfully, student writing groups have the potential to strengthen student writing skills and outputs, as well as deepen interdisciplinary learning. Drawing from Lattuca's four aspects of interdisciplinary learning (relational, mediated, transformative and situated), the article illustrates ways that the writing group helped to promote each aspect of learning and benefit the overall student experience in the program. Reflecting on these experiences, the authors propose six practical considerations for establishing writing groups in interdisciplinary programs: vision and purpose; dedicated time and space; institutional support; readings or educational material; socialization opportunities; and shared responsibility. Administrators, students, faculty members and support staff involved in the delivery of interdisciplinary doctoral programs are called upon to consider the introduction and/or strengthening of writing groups for the purpose of enhanced interdisciplinary learning.
\end{abstract}




\section{Introduction}

W hether loved or loathed, writing is an inevitable aspect of pursuing a doctoral degree. For many doctoral students, in addition to planning, drafting, revising, and finalizing a Ph.D thesis, writing is central throughout the research process (Aitchison and Lee, 2006). And on top of this, writing is typically a major component of coursework-where student performance impacts their competitiveness for awards and funding-and is required to build a record of academic publications, conference submissions and funding applications that are crucial for career progression beyond the doctoral program. Challenges such as writing anxiety, writing apprehension and writers' block pose serious concerns when they jeopardize the academic and personal wellbeing of students (Wynne et al., 2014). Finding ways to encourage writing capabilities in doctoral students stands to promote their academic success and, by extension, bolster the reputation and visibility of their institution and program of study (Kamler and Thomson, 2006).

Yet, can fostering improved writing have additional benefits for academic acculturation and learning among doctoral students?

Literature about writing as a "social practice" indicates that it may (Kamler and Thomson, 2006, 2008; Lillis and Turner, 2001). The notion of writing as a social practice suggests that academic writing is not a wholly solitary task, but rather one that is often undertaken in collaboration, or at least consultation, with others. It also acknowledges that the process of academic writing is embedded in institutional conventions and contexts. As such, social relations and knowledge of disciplinary practices and politics are intrinsic to how students learn to write (Baynham, 2002). For many students, writing at a doctoral level represents an entry into existing discourses within a given discipline or subject area; hence, writing is a fundamental way for doctoral students to develop their sense of professional academic identity (Cuthbert et al., 2009).

The question of how to effectively support writing as a social practice is particularly perplexing within interdisciplinary doctoral programs, given the often conflicting, overlapping or blurred disciplinary perspectives that address a shared area of research. Whereas single- or multi-disciplinary spaces accommodate one or multiple distinct disciplinary commitments, interdisciplinary spaces foster deeper interaction and integration of different disciplinary perspectives (Sá, 2008). In exploring definitions of interdisciplinarity, Borrego and Newswander (2010) distinguish between "team-based collaboration" (a common application in engineering and science fields, where disciplinary experts converge to work together), and what they view to be a "deep" definition of the term stemming from the humanities, which focuses on individual intellectual processes that synthesize concepts from multiple disciplines. Given that interdisciplinary doctoral programs generally focus on educating individuals in interdisciplinary methods, we adopt this latter conceptualization of the term. In keeping with this application, Lattuca (2002) proposes four aspects of interdisciplinary learning, which are catalyzed by student socialization processes: relational, mediated, transformative, and situated (Table 1) (Lattuca, 2002; Manathunga et al., 2006).

The nature of interdisciplinary programs presents two major considerations for furthering the social practice of writing among doctoral students. First, achieving an interdisciplinary learning environment is inherently challenging given that institutions (and their faculty members) tend to be organized according to single disciplines (Holley, 2009). High-quality interdisciplinary programs commit intention and resources to encourage collaboration across disciplines, promoting learning communities that are diverse and participatory (Newswander and Borrego, 2009).

Second, the acculturation of doctoral students to interdisciplinary norms, values and beliefs-which also inform writing practices-requires deliberate efforts to foster student socialization (Boden et al., 2011; Holley, 2009). This acculturation process is particularly resonant in interdisciplinary programs. While exposure to interdisciplinarity as a theoretical perspective may be a focus of core coursework, students may be expected to pursue their own interdisciplinary research interests within the program.

In this article we (doctoral students and faculty in the Interdisciplinary School of Health Sciences at the University of Ottawa) present our firsthand experiences of establishing and participating in a writing group initiative, which in its mission of strengthening the writing capabilities of its membership, has also enhanced the interdisciplinary learning environment in our doctoral program. This article aims to: explain how our writing group serves as a means for interdisciplinary learning; present general considerations for strengthening the potential of writing groups for this purpose; and advocate for the wider integration of writing groups within interdisciplinary doctoral programs. In this article, we first briefly define writing groups and their application in academic and interdisciplinary settings. Then, we detail our experiences establishing a writing group in the interdisciplinary Population Health Ph.D Program and consider ways that our writing group promotes the enhancement of interdisciplinary learning, referring to Lattuca's (2002) four aspects of interdisciplinary learning ${ }^{1}$. Finally, drawing from our experiences, we propose practical considerations to establish writing groups in interdisciplinary doctoral programs, and conclude by outlining wider lessons that can be drawn for the establishment of writing groups in interdisciplinary graduate programs, including the rationale for providing strong institutional support.

\section{Writing groups}

Writing groups, broadly defined, consist of two or more participants who congregate with the common purpose of doing, discussing or sharing writing projects (Aitchison and Guerin, 2014). Writing groups that encourage social connections throughout the process of writing are increasingly recognized as a means to develop critical writing competencies through peer-learning in higher education (Aitchison, 2009; Larcombe et al., 2007; Lee and Boud, 2003; Maher et al., 2008). Social in nature, such groups

Table 1 Aspects of interdisciplinary learning.

\section{Aspect of interdisciplinary learning Description}

Relational

Mediated

Transformative

Situated
The relational component refers to the spaces and opportunities for interdisciplinary dialog.

Mediated learning encompasses interaction with others and engagement with texts and tools from various disciplines

Transformative learning integrates knowledge yielding original, creative outputs.

Situated learning occurs within specific personal, interpersonal and communal contexts that enable interdisciplinary exchanges. 
provide context to inform the practice of writing and student mentoring by faculty and peers. When successful, the benefits of participating in writing groups are numerous: writing groups can serve as supportive communities, encourage daily writing practices, improve language and writing skills, facilitate new insights, and bolster the confidence and writing self-efficacy of participants (Aitchison, 2009; Cuthbert and Spark, 2008; Guerin et al., 2013; Larcombe et al., 2007; Maher et al., 2008).

Writing groups constitute a promising strategy to facilitate meaningful student engagement and socialization surrounding the social practice of writing in interdisciplinary programs. Previous studies of multi-disciplinary writing groups have found them to be a beneficial forum, for example, encouraging graduate students to develop a sense of professional identity by serving as proponents for their respective disciplines, (Cuthbert et al., 2009) and pushing students to practice communicating ideas to academically-diverse audiences (Guerin et al., 2013). To date, however, there is a paucity of literature that specifically addresses writing groups in interdisciplinary doctoral programs and how they may support student learning.

Case study: the Population Health Writing Group. The following case study describes the development of a student writing group within the interdisciplinary Population Health Ph.D Program at the University of Ottawa ${ }^{2}$. The creation of our Writing Group was student initiated, inspired by students' prior exposure to writing groups in other faculties and through institution-wide writing support programs ${ }^{3}$. We note below how all coauthors have been involved as participants and/or facilitators in the Writing Group and why this initiative received strong institutional support.

The first iteration of the Writing Group was launched in April 2018, with the following arrangements: (1) a faculty member in the Program (Tracey O'Sullivan (TO)) was invited to co-facilitate the group alongside a student facilitator (Nicole Bergen (NB)); (2) a dedicated space at the institution was secured to hold meetings; and (3) financial sponsorship was obtained from the Population Health Ph.D Program for refreshments ${ }^{4}$. The original goal of the group was to support one another in developing a daily writing practice and independently preparing articles to submit for publication in a peer-reviewed journal. To recruit participants an email invitation was sent to all students enrolled in the program. The group met 12 times over the summer semester (initially weekly, and then biweekly), and followed the approach outlined in the book Writing your journal article in twelve weeks: A guide to academic publishing success by Wendy Laura Belcher (Belcher, 2009). At the first meeting, we established an online space to set goals, report progress on goals, and share writing-related resources. Co-authors Alzahra Hudani (AH) and Selim Khan (SK) were among the regular attendees.

Meetings during this first summer session lasted $1 \mathrm{~h}$, and consisted of a discussion about writing progress since the last meeting, strategies for overcoming obstacles, and goal setting for the coming weeks. Discussions were loosely framed around weekly readings from Belcher (2009), though we also addressed emergent topics related to writing and publishing. While most participants convened in person, students occasionally joined the meetings remotely using online video conferencing software. By the end of the 12-week session, at least five of the student participants submitted one or more papers for publication. The final meeting of the summer session was a mini writing retreat, consisting of a half-day of writing at a café in the morning followed by a hike in the afternoon.

A second iteration of the Writing Group (fall session) spanned September to December 2018. The invitation to participate was an open invitation to all students that welcomed attendance on a drop-in basis. Given the strong momentum from the summer session, the fall session launched with similar goals, though a more relaxed structure: the $1 \mathrm{~h}$, weekly meetings provided an opportunity for students to discuss any writing endeavor (not necessarily a dedicated project to move forward throughout the semester), and optional weekly readings from Paul Silvia's book Write it up: practical strategies for writing and publishing journal articles. (Silvia, 2015) We introduced an afternoon writing component, whereby students could remain in the space after the meeting to work on their independent writing projects. Compared to the summer session, the fall session had less emphasis on goal setting and accountability, though more opportunity for broader discussions about writing and the research process. The fall session took place across two locations at the institution, with ongoing facilitation support from TO, the program director and one of the coauthors, and financial support from the Population Health Ph.D Program. All other coauthors (NB, AH, SK and Natalie Montgomery (NM)) were among the 15 students who attended during the fall session, with $\mathrm{NB}$ and NM sharing co-facilitator duties. Teaching, academic and work obligations were a barrier for some students intending to attend more regularly. Similar to summer, the fall session culminated with a mini writing retreat and social activity.

In the following winter session (January to April, 2019), facilitator duties were distributed amongst the group with a rotating student volunteer leading the weekly discussion featuring an article of their choice. Sharing the responsibility amongst the group lessened the burden and fostered a sense of buy-in for all Population Health Writing Group members. This was important to support each other each week and benefit from a variety of different interdisciplinary perspectives. Faculty members were periodically invited to meetings to talk about their personal experiences and share advice related to writing topics. This strategy was employed to foster participation of other professors and expand opportunities for students to strengthen their professional networks.

\section{Enhanced interdisciplinary learning}

The coauthors reflected upon how features of the Population Health Writing Group address relational, mediated, transformative and situated aspects of interdisciplinary learning, detailed below. Overall, our observations and personal experiences in the Writing Group suggest that the student engagement, interaction and dialogs enabled by the Writing Group have been instrumental for enhanced overall student experiences in the program of study. From an institutional perspective, having a weekly gathering to support writing created a new channel for mentoring and provided an opportunity for the program director to interact with students on a weekly basis. This was important because at that time the program spanned five faculties; the writing group was an opportunity to foster cohesion and support many students who were finished their coursework and did not have regularly scheduled meetings on campus to connect with peers and faculty.

Relational aspects. This component refers to the notion that learning is facilitated by others in the work or study environment who influence and promote interdisciplinarity in critical ways (Lattuca, 2002). For example, it encompasses the spaces and opportunities for interdisciplinary dialog. The Population Health Writing Group established a physical space and time for students to convene, and introduced a new opportunity for interdisciplinary dialog. We successfully secured a "neutral" meeting space that was not linked to any particular disciplinary department. We feel that this contributed to promoting a sense of 
inclusion for doctoral students with affiliations across different faculties, as the Group was attended by students with diverse research interests and backgrounds. Likewise, the participation of the Program Director (TO) as a co-facilitator underscored the interdisciplinary nature of the environment, as she is someone known to students for her leadership in promoting interdisciplinary learning environments. Other small touches, such as providing refreshments, ritualized aspects of the encounter and made the space inviting and comfortable.

Having a dedicated physical space is a beneficial, though often overlooked, aspect of interdisciplinary encounters. One particular challenge stems from the dilemma of requiring a common interdisciplinary space in order to effectively congregate to then rally for sufficient support for a common interdisciplinary space (Boden et al., 2011). The Population Health Writing Group serves as, at minimum, one such space to foster a sense of belonging to the program and build momentum for further interdisciplinary dialog opportunities.

Mediated aspects. Mediated learning is the participation in multiple disciplinary communities of practice, to variable extents, depending on the learner's interests and purposes (Lattuca, 2002). Learners may seek interaction with others with different disciplinary backgrounds, and engagement with texts and tools from various disciplines.

The Writing Group's weekly readings and discussion topics, which spanned a variety of both general and discipline-specific issues, facilitated mediated aspects of interdisciplinary learning. These mediated exchanges provided structure to the Group meetings, and facilitated meaningful interactions. The depth of student interactions evolved organically through prolonged engagement with fellow Writing Group participants and their work. In many instances, Writing Group participants exchanged their written work in an ad hoc peer-review process. Giving and receiving feedback from peers in the context of writing groups has been found to be an important tool for learning; in particular, students benefit from the exercise of communicating and explaining their feedback to their peers (Aitchison, 2009).

The ongoing involvement of the Population Health Program Director as a co-facilitator has helped to ensure mediated exchanges surrounding writing by broadening discussions to encompass interdisciplinary perspectives. Additionally, the time dedicated to the Writing Group by the Program Director conveys institutional academic support for students. Student experience and professional skill development are both institutional priorities within this program, and therefore the provision of faculty support for this initiative was an obvious choice for the faculty administering the program. Perceived organizational support through interpersonal connections with supervisors/ employers is associated with need satisfaction as well as work satisfaction, happiness and self-realization (Gillet et al., 2012).

Transformative aspects. Transformative learning occurs as mediated tools are put to new uses; often, tools are purposefully adapted for these new uses (Lattuca, 2002). Transformative learning integrates knowledge yielding original, creative outputs. Evidence of transformative learning in our Writing Group was apparent, though often indirectly. Students who regularly attended the weekly meetings were exposed to various research methods and viewpoints from peers, and could practice engaging in dialog surrounding diverse topics. Having the opportunity to use the Writing Group as a sounding board for projects, participants were positioned to receive and integrate peer feedback to enhance their writing outputs. This process has the potential to enrich their work, as students in interdisciplinary doctoral programs demonstrate a wide variety of experiences and backgrounds, academically and otherwise.

Although difficult to observe, transformative learning is also encouraged through the student socialization aspect of the writing groups. Kamler and Thomson (2006) demonstrate the interdependence of multiple layers of discourse in the production of scholarly writing: the written text; the production and interpretation of text; and the abstract sociocultural practices in which discourse is embedded. Acknowledging that doctoral students tend to have low awareness of the sociocultural practices surrounding writing, the authors suggest that gaining an appreciation for this context is important to fully understand their contribution to knowledge in the field (Kamler and Thomson, 2006).

Situated aspects. The situated aspect refers to the wider context that affects how interdisciplinary learning advances, encompassing the specific personal, interpersonal and communal contexts that enable interdisciplinary exchanges (Lattuca, 2002). The Population Health Writing Group cultivated a deliberate context for interdisciplinary exchanges, promoting situated aspects of learning. This context reflects the goals and purpose of the group (i.e., for interdisciplinary doctoral students to support one another in daily writing practices and writing for publication), as well as emergent contextual practices within the group (e.g., setting goals, sharing resources and peer-reviewing). The Writing Group has remained a dedicated space for students in the Population Health Ph.D Program, despite requests from students in other programs to join. The choice for the Writing Group to remain as a Population Health Ph.D Program initiative has allowed it to remain an environment for interdisciplinary exchanges: all participants have a vested interest in the interdisciplinary nature of the discussions. This has also ensured ongoing support from the faculty. The Population Health Writing Group enabled us, as interdisciplinary doctoral students and faculty, to be less centralized in our various departments, and helped us to break from working on projects in seclusion with limited to no program interactivity and engagement across faculties. In turn, this opportunity brought meaning, inclusivity and rigor to our studies beyond first-year coursework, and allowed our Group to focus on developing routine support for each other alongside a strong work ethic with our manuscripts.

Decisions surrounding the structure and implementation of the Writing Group were informed through ongoing consultation with students in the program, though remained within the overall vision for the group. While the degree of structure in the Writing Group varied from the more structured summer session to the more relaxed fall and winter sessions, no one particular style is needed for writing groups to be successful, provided that the members are committed and invested in one another (Lee and Boud, 2003).

\section{Practical considerations}

The experience of establishing a writing group in the interdisciplinary Population Health Ph.D Program has led us to consider how such groups could be oriented towards enhanced interdisciplinary learning. The coauthors undertook a critical reflection of the group over the first three sessions, and propose six practical considerations for developing writing groups in interdisciplinary doctoral programs.

Vision and purpose. Having a purpose directed towards creating opportunities for interdisciplinary encounters is helpful to maintain an interdisciplinary focus. It also serves to articulate the aims of the group to the student body and faculty members. For 
example, a greater emphasis on flexibility and inclusion in the fall iteration of our writing group prompted us to adopt strategies to encourage drop-in attendance and reach a larger number of students. While developing writing capabilities has remained the primary focus of the group (indicated, above all, in its name) acknowledging the group as an opportunity to promote aspects of interdisciplinary learning may help to strengthen such outcomes.

Dedicated time and space. Securing a neutral space (i.e., one that is not associated with a particular discipline) for interdisciplinary writing groups promotes an inclusive environment. It helps to establish consistency and positions the group as an ongoing fixture of the program (thereby promoting its sustainability). In the case of our group, maintaining the space for individual writing following the weekly meeting provided additional opportunities for engagement and encouraged on site writing. Accommodating students through the option of participating in meetings virtually was another way to ensure that students engaged in diverse research activities (e.g., field work or conferences) could participate.

Institutional support. Support from the institution, faculty and program -through financing, participation, training or otherwise - substantiates the experience and thereby promotes the sustainability of the group. It can also support Strategic Enrollment Management by creating additional opportunities to mentor students throughout their academic trajectories. Students can benefit from the expertise of faculty members, while regular contact with students helps faculty members remain engaged and invested in their success. Feedback from the coauthors (and informally from other participants in the group) suggests that the engagement of faculty members has enhanced their experience in the group and motivated them to attend. The presence and support of faculty members allowed this initiative to feel officially sanctioned and structured by offering a sense of mutual commitment and accountability between the program and students, and helped maintain ongoing participation and contributions. Not only did faculty members attend the group on a weekly basis, but select faculty members were invited to give guest lectures where they touched upon writing in different contexts, lending their personal experiences.

Readings or educational material. Identifying texts that have an interdisciplinary focus or that are applicable across multiple disciplines provides a road map for broad discussions to the benefit of a variety of students across different faculties. The practical nature of a writing group-i.e., to develop written outputs-often lends itself to types of educational materials that complement what students may encounter in their coursework or program of study. Selecting materials that have applications across disciplines helps to orient discussions thusly. In our experiences, non-mandatory readings provided a useful common starting point for facilitated discussions while maintaining an inclusive environment for all students to attend (regardless of whether they had completed the reading).

Social aspect. Creating opportunities for student socialization builds connections and social capital between students with different disciplinary backgrounds. Socialization may be encouraged through structured writing group activities, or it may occur organically among regular participants. Building momentum for supplementary activities, such as writing retreats, group writing sessions, guest lectures, gallery visits, hiking trips and shared meals, may enhance the social environment.
Shared responsibility. Cultivating a sense of shared responsibility encourages participation, buy-in and ownership, and promotes the representation of a variety of perspectives - a notion that is particularly resonant in interdisciplinary graduate programs. Shared responsibility may be enacted through rotating leadership roles.

\section{Conclusion}

While the general benefits of participating in writing groups have been well documented, few studies to date have explored how the benefits of writing groups can be harnessed to strengthen learning opportunities within interdisciplinary graduate programs. Drawing on Lattuca's (2002) four aspects of interdisciplinary learning provided a suitable framework to guide our reflections on the impact of our Writing Group. We acknowledge that other components of interdisciplinary learning may also be pertinent and relevant. For instance, the iterative aspect of interdisciplinary learning that occurs through repeated encounters and negotiation emerged over the course of prolonged, regular engagement through the Writing Group.

On a practical note, our experiences establishing a writing group in the interdisciplinary Population Health Ph.D Program illustrated that student, faculty and administrative support were all key to the initial launch of this initiative. Reflecting upon the first three sessions of the writing group, we do not point towards a single formula for success, but rather towards the importance of ongoing engagement and refinement of the delivery-including the structure, reading materials and meeting format-to ensure that the initiative remains relevant to the needs and preferences of the student cohort. In particular, we emphasize that writing groups can be an opportunity to strengthen aspects of interdisciplinary learning, and call for deliberate and ongoing consideration of measures to promote these benefits. The practical considerations highlighted above have helped to identify characteristics of our group that enhance aspects of interdisciplinary learning and that may serve as guidance for establishing writing groups in other interdisciplinary graduate programs.

Given the centrality of writing to the doctoral education experience, both students and faculty stand to benefit from strategies to support the social process of writing. By contributing to enriched student experiences, academic capabilities, and productivity, writing groups constitute a unique opportunity for the marketability of interdisciplinary programs. Acknowledging the growing interest in interdisciplinary graduate programs, we contend that writing groups may have positive implications for the success and future prospects of the program graduates, and in time, student recruitment into the program. Research is warranted to expand upon our experiences, explore diverse aspects of interdisciplinary learning, and compare different models and approaches to delivering writing groups across other interdisciplinary graduate programs.

Received: 17 September 2019; Accepted: 16 January 2020; Published online: 31 January 2020

\section{Notes}

1 We adopted Lattuca's four aspects of interdisciplinary learning to help us guide our reflections and structure our experiences about the Writing Group initiative post hoc. 2 The program spans five faculties: Health Sciences, Medicine, Law (Common Law Section), Social Sciences and the Telfer School of Management. The core competencies of the program emphasize interdisciplinarity, including "acknowledging the disciplinary limits and the input of different disciplines in terms of knowledge, research methods and interventions" (University of Ottawa, 2016). As of early 2019, there were 47 students enrolled in the program. 
3 The structure and objectives of the Writing Group were also informed through consultations with students from the program who were enrolled in a professional skill development course; this course included a focus on developing academic writing competencies.

4 Students took turns providing refreshments to promote a sense of inclusivity and shared responsibility among the participants.

\section{References}

Aitchison C (2009) Writing groups for doctoral education. Stud High Educ 34 (8):905-916

Aitchison C, Guerin C (eds) (2014) Writing groups, pedagogy, theory and practice: An introduction. In: Writing groups for doctoral education and beyond. Routledge. pp. 19-33

Aitchison C, Lee A (2006) Research writing: problems and pedagogies. Teach High Educ 11(3):265-278

Baynham M (2002) Academic writing in new and emergent discipline areas. In: Harrison R, Reeve F, Hanson A, Clarke J (eds) Supporting lifelong learning: perspectives on learning. Routledge, London, pp. 188-202. vol. 1

Belcher WL (2009) Writing your journal article in twelve weeks: a guide to academic publishing success. SAGE Publications Inc, Thousand Oaks, CA

Boden D, Borrego M, Newswander LK (2011) Student socialization in interdisciplinary doctoral education. High Educ 62(6):741-755

Borrego M, Newswander LK (2010) Definitions of interdisciplinary research: toward graduate-level interdisciplinary learning outcomes. Rev High Educ 34 (1):61-84

Cuthbert D, Spark C (2008) Getting a GRiP: examining the outcomes of a pilot program to support graduate research students in writing for publication. Stud High Educ 33(1):77-88

Cuthbert D, Spark C, Burke E (2009) Disciplining writing: the case for multidisciplinary writing groups to support writing for publication by higher degree by research candidates in the humanities, arts and social sciences. High Educ Res Dev 28(2):137-149

Gillet N, Fouquereau E, Forest J, Brunault P, Colombat P (2012) The impact of organizational factors on psychological needs and their relations with wellbeing. J Bus Psychol 27(4):437-450

Guerin C, Xafis V, Doda DV, Gillam MH, Larg AJ, Luckner H, Xu C (2013) Diversity in collaborative research communities: a multicultural, multidisciplinary thesis writing group in public health. Stud Continuing Educ 35 (1):65-81

Holley K (2009) The challenge of an interdisciplinary curriculum: a cultural analysis of a doctoral-degree program in neuroscience. High Educ 58 (2):241-255

Kamler B, Thomson P (2006) Helping doctoral students write: pedagogies for supervision. Routledge, London; New York, NY

Kamler B, Thomson P (2008) The failure of dissertation advice books: toward alternative pedagogies for doctoral writing. Educ Researcher 37 (8):507-514

Larcombe W, McCosker A, O'Loughlin K (2007) Supporting education PhD and DEd students to become confident academic writers: An evaluation of thesis writers' circles. J Univ Teach. Learn. Pract. 4:54-63

Lattuca LR (2002) Learning interdisciplinarity: sociocultural perspectives on academic work. J High Educ 73(6):711-739

Lee A, Boud D (2003) Writing groups, change and academic identity: research development as local practice. Stud High Educ 28(2):187-200
Lillis T, Turner J (2001) Student writing in higher education: contemporary confusion, traditional concerns. Teach High Educ 6(1):57-68

Maher D, Seaton L, McMullen C, Fitzgerald T, Otsuji E, Lee A (2008) "Becoming and being writers": the experiences of doctoral students in writing groups. Stud Continuing Educ 30(3):263-275

Manathunga C, Lant P, Mellick G (2006) Imagining an interdisciplinary doctoral pedagogy. Teach High Educ 11(3):365-379

Newswander LK, Borrego M (2009) Engagement in two interdisciplinary graduate programs. High Educ 58(4):551-562

Sá CM (2008) “Interdisciplinary strategies" in U.S. research universities. High Educ 55(5):537-552

Silvia PJ (2015) Write it up: practical strategies for writing and publishing journal articles. American Psychological Association, Washington, DC

University of Ottawa. (2016) Phd in population health: student handbook 2016/2017. University of Ottawa. Retrieved from https://health.uottawa.ca/interdisciplinary/ sites/health.uottawa.ca.interdisciplinary/files/pop_student_handbook_2016.pdf

Wynne C, Guo YJ, Wang SC (2014) Writing anxiety groups: a creative approach for graduate students. J Creativity Ment Health 9(3):366-379

\section{Acknowledgements}

We thank the students and faculty members who have attended and supported the writing group.

\section{Competing interests}

The authors declare no competing interests.

\section{Additional information}

Correspondence and requests for materials should be addressed to N.B.

\section{Reprints and permission information is available at http://www.nature.com/reprints}

Publisher's note Springer Nature remains neutral with regard to jurisdictional claims in published maps and institutional affiliations.

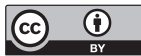

Open Access This article is licensed under a Creative Commons Attribution 4.0 International License, which permits use, sharing, adaptation, distribution and reproduction in any medium or format, as long as you give appropriate credit to the original author(s) and the source, provide a link to the Creative Commons license, and indicate if changes were made. The images or other third party material in this article are included in the article's Creative Commons license, unless indicated otherwise in a credit line to the material. If material is not included in the article's Creative Commons license and your intended use is not permitted by statutory regulation or exceeds the permitted use, you will need to obtain permission directly from the copyright holder. To view a copy of this license, visit http://creativecommons.org/ licenses/by/4.0/.

(C) The Author(s) 2020 